\title{
The Syntactic Status of Arabic Clauses Introduced by Pinna A Minimalist Study
}

\author{
Mansour Qazan Alotaibi ${ }^{1}$ \\ ${ }^{1}$ Department of Arabic, Prince Sattam bin Abdulaziz University, Saudi Arabia \\ Correspondence: Mansour Qazan Alotaibi, Department of Arabic, College of Education, Prince Sattam bin \\ Abdulaziz University, P. O. Box 176, Alkharj, 11942, Saudi Arabia. E-mail: mq.alotaibi@psau.edu.sa
}

Received: December 2, 2018 Accepted: December 23, 2018 Online Published: January 28, 2019

doi:10.5539/ells.v9n1p70 URL: https://doi.org/10.5539/ells.v9n1p70

\begin{abstract}
A Standard Arabic (SA) complementizer known as Pinna poses a restriction on word orders in the clause it introduces and induces accusative Case-marking on the otherwise nominative preverbal NPs (Note1). Following Chomsky's (2001) account of the morphosyntax of Case, this paper argues that Pinna is a Case assigner and thus it carries an uninterpretable Case feature that determines the value which it assigns to an unvalued Case feature concerning accessible goal within A-bar projection. The paper shows that this argument captures the asymmetrical word order between clauses introduced by ?inna and those headed by null CPs.
\end{abstract}

Keywords: Arabic, complementizer, case marking, word order, minimalism

\section{Introduction}

Arabic allows both subject-initial and verb-initial clauses. As sentences (1a) and (1b) demonstrate, respectively, the verb can either precedes or follows the subject:
1a) 1-Pawlaad-u qara?-uu 1-kitaab-a
the-boys-NOM read.3PM the-book-ACC
'The boys read the book.'
1b) qara?a 1-?awlaad-u 1-kitaab-a
read.3SM the-boys-NOM the-book-ACC
'The boys read the book.'

The verb also shows full agreement in subject-initial-clauses (1a), but partial agreement in verb-initial-clauses (1b) in person and gender only and not in number as the former does.

In addition, Arabic is considered as a subject pro-drop language. The verb shows full agreement when its subject is not overt:

2) qara?-uu 1-kitaab-Acc
read.3pm the-book-Acc
'The boys read the book.'

However, subordinate clauses introduced by Pinna is restricted to subject-initial clauses (Note2). A typical example is given here:
3) qultu Pinna 1-Pawlaad-a qara?uu 1-kitaab-a
said.1S that the-boys-ACC read.3PM the-book-ACC
'I said that the boys read the book.'

As can be seen, Pinna is followed by an accusative NP which can be interpreted as a subject of the following verb. However, this accusative NP is not always interpreted as a subject. The following shows that the accusative NP is interpreted as an object: 


\section{4) qultu Pinna 1-kitaab-a qara?a-hu 1-Pawlaad-u \\ said.1S that the-book-ACC read.3S-it the-boys-NOM}

'I said that (as far) the book, the boys read it.'

Notice that there is a pronominal clitic attached to the verb, a similar construction with no pronominal clitic is ungrammatical:

5)* qultu Pinna 1-kitaab-a qara?a l-Pawlaad-u
said.1S that the-book-ACC read.3S the-boys-NOM
'I said that (as far) the book, the boys read it.'

Notice also that you cannot have a gap in the preverbal position. As stated above, preverbal subjects are optional in null CPs, but it is not possible to have a gap in the embedded preverbal position (Here and subsequently the paper marks gaps by ' $\_$'):
6)* qultu Pinna
qara?-uu 1-kitaab-a
said.1S that
read.3PM the-book-ACC

'I said that the boys read the book.'

Thus, the example above, where the subject has been omitted, is ungrammatical. However, a similar example with a pronominal clitic attached to ?inna is grammatical:

7) qultu Pinna-hum qara?-uu 1-kitaab-a

said.1S that-they read.3PM the-book-ACC

'I said that the boys read the book.'

Note also that verb-initial clauses cannot occur in the domain of Pinna:
8)* qultu Pinna qara?a
1-Pawlaad-a 1-kitaab-a
said.1S that read.3SM the-boys- ACC the-book-ACC

'I said that the boys read the book.'

This paper attempts to provide an account of accusative Case checking in this construction in which the accusative preverbal NPs are embedded under a Case-assigning complementizer. In addition, it will account for the restriction that is imposed by ?inna on its clauses.

\section{Theoretical Background}

This section introduces the major concepts of the Minimalist program (MP) which has played a crucial role in the analysis introduced in the paper.

\subsection{Merge and Move}

Chomsky (1995) argues that the human language faculty consists of lexicons and derivational systems. There are two major operations: Select and Merge which operate over a group of lexical items named Numeration to form syntactic structures. The language faculty allows these syntactic structures to appear only in a binary set. Of the two, Merge is that operation which acts free in the syntactic component of Language (Chomsky, 2004, p. 108). It is a combinational operation which forms a syntactic object by merging two linguistics expressions $(\alpha$ and $\beta)$ and form a new unified linguistic expression, resulting in the structure:

9)

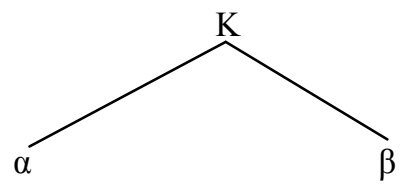

In this sense, Merge is a recursive structure-building process operating on linguistic expressions based on their selectional features. For example, an $\mathrm{X}$ is a head and carries an uninterpretable feature which requires it to merge with a ZP to form an XP, resulting in deleting X's selectional feature. This is the first instance of Merge, called external Merge. The other instance is Internal Merge which is understood as Move (Chomsky, 2001). Move deals with linguistic expressions and phrases. It applies to the merged linguistic expressions; it places a copy of the object in another position. Move is triggered by the requirement to satisfy the Edge feature (EF) of a specific functional head. Move is required to take a place early in the syntax before the operation Spell Out which 
transfers the structure to the phonological component (PF) and the semantic component (LF) (Note 3). PF and $\mathrm{LF}$ are operations which when the syntactic structure is completed is sent to.

\subsection{Interpretable vs. Uninterpretable Features}

Features are divided into two kinds of features: interpretable and uninterpretable features. Some of them are legible by semantic component, whereas others are not. Those with semantic component would get a semantic interpretation and thus would be interpretable, whereas the others that would not get a semantic interpretation and thus they would be uninterpretable and this is due to the absence of the semantic component.

Likewise, functional and lexical categories too have a set of features. Functional heads carry 'formal features' such as person, number and gender (Chomsky, 2001). They are uninterpretable, and thus enter the derivation unvalued as they have no effect on semantic interpretation of heads such as $\mathrm{C}, \mathrm{T}$, and $v$ at LF. By contrast, features on nominal expressions are important for their semantic interpretation, and thus would enter the derivation valued. However, the Case feature on nominal expressions has no semantic role, and thus it is uninterpretable at LF.

\subsection{Agree}

Unlike Merge, Agree is concerned with features rather that with lexical items. Its crucial function is to value these features which enter the derivation unvalued and to delete uninterpretable features that have no semantic content. Agree establishes a relation between Probe and Goal both of which have to be active with uninterpretable features (Note 4). In order to value its unvalued uninterpretable features, Probe searches for an active Goal in its c-commanding domain. A Probe is an uninterpretable feature carried by a minimal projection, while its Goal feature is interpretable of the same type carried by a maximal projection.

\subsection{Case Assignment}

In the Minimalist Programme, Case assignment continues to play a major role in the derivation of syntax. Abstract Case, in the original presentation of Case theory in Chomsky (1980), is related to the morphological property Case. The formal features that regulate the distribution of NPs are the same features that are overtly considered as Case morphology in some languages. Within GB framework, Chomsky (1981) proposed the Case Filter as a solution to the ambiguity of the distribution of lexical NP subjects in infinitive clauses in English as illustrated in (10):

10a) Leo decided [(*Lina/himself) to leave].

b) Leo believed [Lina to be a genius].

c) Leo decided [for Lina to leave].

d) For Leo to win would be great.

e)* Leo to win would be great.

The subject cannot be overt in (10a, e), but this restriction is relaxed when the infinitival clause functions as a complement of a specific class of matrix verbs like the verb believe (10b), or when the infinitival clause includes the prepositional complementizer for $(10 \mathrm{c}, \mathrm{d})$. Where the overt lexical NP subject is not permitted, the subject of the infinitive is considered as a silent pronominal element PRO. This assumption is the key of the Case Theory which proposes that all lexical NPs require Case (Chomsky, 1981, p. 49). A rather basic proposal of Case assignment for English is in (11):

11a) subject of tensed clause: nominative

b) object of verb: accusative

c) object of preposition: accusative (or oblique)

This is to say that verbs and prepositions have the distinctive properties of being Case assigners and this property accounts for why only verb and preposition in English take NP complements. Nouns and adjectives are not Case assigners and therefore are restricted to CP and PP complements (Bobaljik \& Wurmbrand, 2011, p. 46).

For Minimalism, the central study of Case Theory is to investigate the differences between nominative and accusative Case assignments and to develop a uniform theory with them. To achieve that, Chomsky (1991) proposal was to assimilate accusative Case assignment to the similar type of structural configuration as nominative, namely Spec(ifier)-head relation (for more information, see Koopman, 2006) (Note 5). The proposal assumes that all Case assignments are subject to c-command and locality (Note 6), the relation is later termed Agree (Chomsky, 2000) (Note 7). This suggests that all subjects in Spec-IP (Spec-TP, in the most recent 
Minimalist works) are moved there from a lower position (this proposal is originally proposed in Koopman \& Sportiche, 1991).

The mechanism of the uniform Case assignment considers the functional versus lexical differences in the Case assigners. Chomsky (1991) and Johnson (1991) assume that VP-external functional projection is responsible for Case on objects, and this assumption in turn leads to unify a proposal that Case is assigned by functional heads (see Wurmbrand, 2001, for empirical evidence).

Under the most recent Minimalist conceptions, Case is generalized as part of a system of uninterpretable features that takes a place at the core of the linguistic coding of what Chomsky $(2004$, p. 7$)$ called 'duality of semantic': one part is the argument structure and the second is the information structure. So, Case features permit the proper working of the Probe-Goal system, a feature-checking mechanism that was not understood in GB framework (see also Pesetsky \& Torrego, 2001, for another speculation).

However, the literature (e.g., Harley, 1995; Schutze 1997; Ouhalla, 1994; Aoun et al., 2010) shows that Universal Grammar contains a notion of 'Default Case' which has a mechanism different from the one discussed above. The notion of 'default Case' is advanced in Marantz (1991) as the Case that does not interact with the Case Filter or 'feature-Checking'. So, what is mechanism of the Default Case? It is the mechanism that is used to spell out NPs that are not in association with the mechanism of the feature-checking. Thus, I assume that the model of grammar schematically follows three nominals through the syntactic derivation: two with an uninterpretable (ACC or GEN) feature to be checked and one with no Case (NOM) feature. The NPs with NOM Case feature survives at Spell-out level, given that it never had any uninterpretable features to be checked.

Before proceeding to discussions, one reviewer suggests that I should provide a section on Pinna and its sisters and explain the reason behind the limitation to Pinna.

\section{The Nature of Pinna and Its Sisters}

The structural theme of subject + predicate is subjected to interactions by the association of Pinna or one of its sisters. The distinguishing feature of Pinna and its sisters is their appearance with a subject in the accusative Case and a predicate in the nominative Case. This property is explained in the traditional Arabic grammar by invoking their similarities to the transitive verbs showing the word order VOS. Each of these particles changes the grammar and the semantic of subject + predicate structure when it associated with. They reflect in its totality a degree of lack or absoluteness commensurate with the totality of these relative grammatical and semantic components. Leaving aside the semantic component, the grammatical changes are the function of the computation of the two Cases over the subject and the predicate. This computation results in a unique structure type; accusative subject and nominative predicate. While the subject receives an accusative Case the predicates remains in its nominative Case. These particles are: Pinna (indeed, that), ?anna (that), ka 2anna (looks-like), laakinna (but), layta (would, if only, wish), and la?alla (perhaps). They are illustrated in (12), respectively:
12a) Pinna 1-masafat-a qaSiirat-un
'The distance is, indeed, short'
Indeed the-distance-ACC short-NOM
b) Calimtu Panna 1-masafat-a qaSiirat-un
knew.3S that the-distance-ACC short-NOM
'I knew that the distance is short'
c) kPanna 1-masafat-a qaSiirat-un
looks-like the-distance-ACC short-NOM
'It looks like that the distance is short'
but the-distance-ACC short-NOM
d) lakinna 1-masafat-a qaSiirat-un
'But the distance is short'
e) layta 1-masafat-a qaSiirat-un
wish the-distance-ACC short-NOM
'Wishing the distance is short'
f) laSalla 1-masafat-a qaSiirat-un 
perhaps the-distance-ACC short-NOM

'Perhaps the distance is short'

\section{Discussions}

In section (1), it has been shown that the adjacent of the complementizer must be in accusative Case:

12) qultu Pinna T-tabiib-a waSala

said.1SM that the-doctor-ACC arrived.3SM

'I said that the doctor arrived.'

Pinna heads finite clauses and the embedded preverbal 'subject' NP bears the accusative Case as it is obvious from the accusative Case on T-tabiib-a ( $-a$ is an accusative marker).

The fact that the embedded 'subject' is assigned an accusative Case raises an important question about its status with respect to the Case-assigment. Following the assumption that heads are endowed with Case features which must be checked, Muhammed (2000) assumes that both T and C assign thier Case feature on the embedded preverbal NP (T-tabiib-a, the doctor, in (12)). He adds that the Case feature which is overtly shown on the NP is the one assigned by the highest projectional head, it is $\mathrm{C}$ in this sense. However, it is not clear how it is possible for the head of CP to assign the accusative Case to an element that is located in the specifier position of TP (Spec-TP). The idea that an NP can get more than one Case is required to be constrained by some locality conditions, otherwise it is difficlut to prevent $\mathrm{C}$ (the highst head) from assigning its Case to some element in a lower position. Consider the following example where the predicate preceeds the subject, the subject is located in a lower position (Note 8):
13) qultu
Pinna-hu waSala
T-tabiib-u
said.1SM that-he arrived.3SM the-doctor-NOM

'I said that the doctor arrived.'

Here, the expletive - $h u$ is attached to Pinna but the subject (T-tabiib-u, the doctor) is in a position following the verb and it is in nominative Case that is formally assigned by $T$. The Case here is structural and not inherent since inherent Cases are limited to lexical elements that get a thematic role from the Case assigner which is not the case in (13). In the following, I will argue that the embedded preverbal NP is not located in Spec-TP, but rather in a position located bewteen CP and TP. It is more likely in Spec-TopP.

\subsection{Valued Case Features}

Case in Chomsky (1995) is an unterpretable feature which needs to be checked and deleted. Giving this, and giving that NPs in Spec-TP must be assigned Case as they are in arguemnt position (Chomsky, 1981, 1986) and the head of Spec-TP (or agreement) assigns the nominative Case under some versions of Case Theory, the status of the accusitive NP in Spec-TP would be difficult to explain. Consider the ungrammaticality of the following example in which a gap occurs in the position of direct object of the verb:
14)* Pinna
1-kurat-a
rakala
1-salad-u
that the-ball-ACC
kicked.3SM
the-boy-NOM
'Indeed, the ball, the boy kicked.'

I refer the ungrammaticlaity of (14) to this, following Pesetsky and Torrego (2001), complementizers have some uniterpratable features that must be licensed by an element with interpretable features, I assume that the complementizer Pinna has an uninterpretable Case feature which it must discharge. As simplified in (15), the accusative NP in (14) is a focus-fronting that raises from its original position to the specifier of a functional projection, named FocP, in order to receive a contrastive reading.

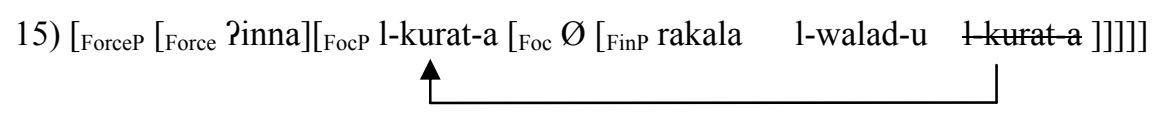

Here, the fronted NP, l-kurat-a, is Case-marked in its canonical position; the accusative Case is a reflection of the sharing properties between the fronted NP and the associated gap. So, if the accusative NP, l-kurat-a, is assigned its accusative Case by virtue of being a nominal goal to the lexical verb, rakala, the Case feature of the complementizer Pinna would remain unchecked. The resulting derivation crashes, as we see from the ungrammaticality of (14). 
However, the sentence in (14) can be repaired by inserting a pronominal clitic that is cliticized onto the verb as an accusative direct object of the verb. A typical example of this construction is given below (the considered clitic is in boldface):

16) Pinna 1-kurat-a rakala-ha 1-walad-u

indeed the-ball-ACC kicked.3SM-it the-boy-NOM

'Indeed, the ball, the boy kicked it.'

Derivationally, the Case feature of the lexical verb is checked against the Case feature on the pronominal clitic. The NP, l-kurat-a, therefore, is not a fronted focused object, but rather it is a left-dislocated topic that occurs in A'-position. Aoun et al. (2010, p. 191) states that clitic-left-dislocations are realized by the appearance of a NP in the left peripheral position of the clause and it is associated with a pronominal clitic inside the clause. Assuming this to be so, the left-dislocated-topic, l-kurat- $u$, is active because its Case feature has not yet been valued. Assuming the complementizer Pinna is a Case-assigner, it carries an uninterpretable Case feature which determines the value that it assigns to an unvalued Case feature on the accessible goal (See Radford, 2009, for more discussions). Consequently, the complementizer Pinna will enter the derivation carrying a feature which enables it to assign accusative Case to the left-dislocated-topic, l-kurat- $u$, the goal, which has an unvalued Case feature.

\subsection{Left-Dislocation Like Property}

First, embedded preverbal accusative NPs obligatory occur in the kind of peripheral position that left-dislocated phrases do. This can be approved by the observation that the embedded preverbal accusative NPs can occur to the left of the copula kaan (=be), but not on the right. Consider the contrast:
17a) ?inna T-taalib-a kaana fii 1-jami?at-i
that the-student-ACC was in the-university-GEN
'indeed, the student was at the university.'
b)* Pinna kaana T-taalib-a fii 1-jami?at-i
that was the-student-ACC in the-university-GEN

'Indeed, the student was at the university.'

The contrast between (17a) and (17b) suggests that the accusative NP should be in a position higher than T.

Second, Soltan (2007) and Alotaibi (2015) argue that preverbal subjects are taken to be genuine topics that are associated with a null resumptive pronoun, pro, in the clause (see also Mohammad, 2000; Fassi Fehri, 1993; Aoun et al., 2010). This approach assumes that post-verbal subjects occur in A-position and receive Structural nominative Case; they get their Case via Agree relation with T. While topics occur in A'-position and appear in the nominative Case by default mechanism in the absence of any overt Case assigner such as an overt $C$ of the Pinna-type. Consider the contrast between following examples:
18a) jaa?a
1-?walaad-u
came.3SM the-boys-NOM
'The boys came'
b)* jaapuu $1-$ ?walaad-u
came.3SM the-boys-NOM
'The boys came'

SA has both preverbal and postverbal subjects and that they differ with respect to the agreement fact. The former triggers number, person and gender agreement, while the latter triggers only person and gender agreement. (18a) is grammatical because of that the verb, jaa?a 'came' agrees with its NP subject in person and gender, but not in number. The verb, however, in (18b) agrees in number as well and hence the sentence in ungrammatical. Now consider the following contrast with subject-initial clauses:
19a) 1-?walaad-u jaa?uu
the-boys-NOM
came.3PM
'The boys came.'
b)* 1-?walaad-u jaa?a 
the-boys-NOM came.3SM

'The boys came'

(19a) is grammatical because of that the subject triggers full agreement, and (19b) is ungrammatical as the subject triggers partial agreement. This suggests that subject-initial clauses (19a) have a pro subject in a post-verbal position. Thus, full agreement is expected with a clause that is includes a pro subject. Assuming this is right, it is plausible to assume that embedded subject-initial clauses have the same analysis and thus the embedded preverbal NP occupies Spec-TopP.

\subsection{The Non-Identity Effects}

Following Miller and Sag (1997), I assume that clitics in Arabic are affixes realizing an otherwise unexpressed argument, and it is not a result of some superficial cliticization (see McCloskey (2006) for more details). I shall call this kind of arguments pro. This pro is in fact the resumptive pronoun. Under the copy theory of movement, it should be clear that the relation between the accusative NP following Pinna and pro is not generated via movement. The theoretical assumptions of Minimalism assume that movement leaves a copy with identical syntactic features. Adger and Ramchand (2005) argue that movement can be involved in cases where the apparently displaced constituent shows the same copy in the base position. More precisely, if the element in the higher position shares it's corresponding in the lower position in respect to agreement, selection and Case-marking, then it can be said that the derivation involves movement, otherwise it should involve base-generation account. In Pinna-clauses, the distribution of Case-marking between the accusative NP and the pro at the foot of the dependency is not the same. This is supported by the following example:

20) Pinna r-rajul-a hajama Palai-hi 1-Psad-u

indeed the-man-ACC attacked.3SM on-it the-lion-NOM

'Indeed, the man, the lion attacked him.'

Here, the topicalized prepositional object bears an accusative Case which is distinct from the one that is associated with in its base position. The accusative Case on the embedded NP would be surprising under the movement account. This would argue that the accusative NP does not originate in an argument position of the lower predicate, but rather it originates in A'-argument, namely the specifier position of Topic projection. (20) is diagrammed in (21):

21) [ForceP[Force Pinna][TopP r-rajul-a [Top Ø] [FinP [Fin Ø][те [Hajama Palai-hi 1-Psad-u]]]]

According to our analysis the accusative Case on the preverbal NP r-raji-a 'the man' is assigned under c-command by an appropriate kind of head. So, since the complementizer Pinna c-commands the subject, $r$-raji-a, and since Pinna is a transitive complementizer, it follows that the NP r-raji-a, the man, will be assigned accusative Case at the stage of derivation shown in (21). However, Pinna can also be followed immediately by a PP which can intervene between Pinna and the accusative NP. The following example expresses this fact:

22) qultu Pinna fii l-bait-i rajul-an

said.1SM that in the-house-GEN man-ACC

'I said that there is a man in the house.'

Mohammad (2000:22) observes that the only predicates can intervene between Pinna and the accusative NP is a PP. A question arises is: why PPs and not others? A similar case is found in Italian sentences structures. For instance, Belletti (2009) observes that post-subject XP can be a PP in VSXP structures, but cannot be a NP:

23a) Ha telefonato Maria al giornale.

Has phoned Maria to the newspaper.

b)* Ha comprato Maria il giornale.

Has bought Maria the newspaper.

Belletti suggests that XPs can be PPs because they PPs do not absorb Case as they need no Case, while NPs need Case. Therefore, Belletti assumes that the intervening of the subject with its already checked Case between XP and the responsible of the Case assignment would cause a Defective Intervention Effect (DIE) (Chomsky, 2000, p.123) which would not allow the Case assigner to check the uninterpretable Case feature of its goal:

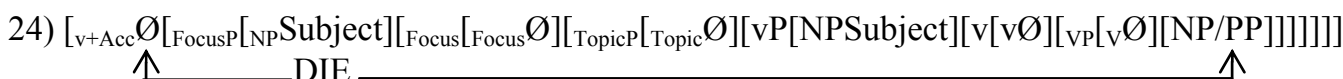


If this analysis is on the right track, it is possible to extend the same analysis to account for the contrast between (22) and (5). If PPs in Arabic do not have a Case feature, then their intervention between the Case assigner Pinna and the accusative NP would not cause any problem as the uninterpretable Case feature on NPs would be able to undergo feature checking.

\section{Conclusion}

This paper has investigated the behavior of Pinna-clauses in Standard Arabic. They differ in their distribution in respect to other clauses in Arabic, but the paper has argued on the basis of Case-assignment that Pinna is a Case-assigner. The findings of this study revels that Pinna assigns the accusative Case to the closest NP via Agree. It has also been argued that the accusative NP following Pinna occupies Spec-TopP and not Spec-TP as proposed in the literature. In addition, this study has accounted for the fact that PPs and not NPs can intervene between the complementizer Pinna and the accusative NP. It has explained this contrast in term of the Defective Intervention Effect in which a probe-goal relation holding between the Probe (Pinna) and the Goal (the accusative NP) is blocked by an intervening active goad such as NPs but not PPs. NPs triggers a Defective Intervention Effect that bars the complementizer from entering into Agree relation with its goal. On the other hand, PPs do not absorb a Case and therefore they are not problematic for the derivation.

\section{Aknowlegements}

This project was supported by the Deanship of Scientific Research at Prince Sattam Bin Abdulaziz University under the research project 5714/02/2016.

\section{References}

Adger, D., \& Ramchand, G. (2005). Merge and Move: Wh-Dependencies Revised. Linguistic Inquiry, 36(2), 161-193. https://doi.org/10.1162/0024389053710729

Alotaibi, M. (2015). Wh-Questions in Modern Standard Arabic: Minimalist and HPSG Approaches. Unpublished $\mathrm{Ph}$. D. Dissertation, University of Essex.

Alsayed, A. (1998). A Government and Binding Approach to Restrictive Relatives, with Particuluar Reference to Restrictive Relatives in Standard Arabic. Unpublished Ph. D. Dissertation, University of Essex.

Alsubhi, A. (2012). The syntax of case and agreement in Standard Arabic: A Minimalist analysis. Unpublished $\mathrm{Ph}$. D. Dissertation, University of Essex.

Aoun, J., Benmamoun, E., \& Choueiri, L. (2010). The Syntax of Arabic. Cambridge: Cambridge University Press.

Belletti, A. (1999). Italian/Romance clitics: Structure and derivation. In H. V. Riemsdijk (Ed.), Clitics in the Languages of Europe (pp. 543-579). Berlin: De Gruyter. https://doi.org/10.1515/9783110804010.543

Borer, H. (1984). Restrictive Relatives in Modern Hebrew. Natural Language and Linguistic Theory, 2, 219-260. https://doi.org/10.1007/BF00133282

Chomsky, N. (1980). On Binding. Linguistic Inquiry, 11, 1-46.

Chomsky, N. (1981). Lectures on Government and Binding. Dordrecht: Foris

Chomsky, N. (1986). Barriers. Cambridge, MA: MIT Press.

Chomsky, N. (1991). Some notes on the economy of derivation and representation. In R. Freidin (Ed.), Principle and Parameters in Comperative Grammar (pp. 417-454). Cambridge, MA: MIT Press.

Chomsky, N. (1995). The Minimalist Program. Cambridge, MA: MIT Press.

Chomsky, N. (2000). Minimalist Inquiries: The Framework. In R. Martin, D. Michaels, \& J. Uriagereka (Eds.), Step by Step: Essays on Minimalist Syntax in Honor of Howard Lasnik. Cambridge, MA: MIT Press.

Chomsky, N. (2001). Derivation by phase. In M. Kenstowicz (Ed.), Ken Hale, A Life in Language (pp. 1-52). Cambridge, MA: MIT Press.

Chomsky, N. (2004). Beyond Explanatory Adequacy. In A. Belletti (Ed.), Structures and Beyond: The Cartography of Syntactic Structures (vol. 3, pp. 104-191). Oxford University Press.

Chomsky, N., \& Howard, L. (1977). Filters and Control. Linguistic Inquiry, 8, 425-504.

Fassi F. A. (1993). Issues in the Structure of Arabic Clauses and Words. Dordrecht: Kluwer Academic.

Harley, H. (1995). Subject, Events, and Licensing. Ph. D. Dissertation, MIT, Cambridge, Mass.

Hornstein, N. (1995). Logical Form: From GB to minimalism. Oxford: Blackwell. 
Johnson, K. (1991). Object Positions. Natural Language and Linguistic Theory, 9, 577-636. https://doi.org/10.1007/BF00134751

Koopman, H. (2006). Agreement Configuration: In Defevse of 'Spec Head'. In C. Boeckx (Ed.), Agreement Systems (pp. 159-199). Amsterdam: Benjamins. https://doi.org/10.1075/la.92.09koo

Koopman, H., \& Sportiche, D. (1991). The Position of Subjects. Lingua, 85, 211-285. https://doi.org/10.1016/0024-3841(91)90022-W

Marantz, A. (1996). Case and Licensing (pp. 234-253). In ESCOL 91: Proceedings of the eighth Eastern States Conference on Linguistics. Columbus: Ohio State University.

McCloskey, J. (1990). Resumptive Pronouns, A'-Binding, and Levels of Representation in Irish. In H. Randall (Ed.), The Syntax of modern Celtic languages (pp. 199-248). New York: Academic Press.

McCloskey, J. (1996). Subjects and Subject Positions in Irish. In B. Borsley \& I. Roberts (Eds.), The Syntax of Celtic Languages (pp. 241-283). Cambridge: Cambridge University Press. https://doi.org/10.1017/CBO9780511586279.009

McCloskey, J. (1997). Subjecthood and Subject positions. In L. Haegeman (Ed.), Elements of Grammar: A Handbook of Generative Syntax (pp. 197-235). Dordrecht: Kluwer. https://doi.org/10.1007/978-94-011-5420-8_5

McCloskey, J. (2006). Resumption. In M. Everaert \& H. V. Riemsdijk (Eds.), The Blackwell Companion to Syntax (pp. 94-117). Blackwell Publishing. https://doi.org/10.1002/9780470996591.ch55

Miller, P., \& Sag, I. A. (1997). French clitic movement without clitics or movement. Natural Language and Linguistic Theory, 15, 573-639. https://doi.org/10.1023/A:1005815413834

Mohammad, M. (2000). Word Order, Agreement and Pronominalization in Standard and Palestinian Arabic. Amsterdam/Philadelphia: John Benjamins Publishing Company. https://doi.org/10.1075/cilt.181

Ouhalla, J. (1994). Focus in Standard Arabic. Linguistics in Postdam, 1, 65-92.

Ouhalla, J. (1997). Remarks on focus in Standard Arabic. In M. Eid \& R. R. Ratcliffe (Eds.), Perspectives on Arabic Linguistics X: Papers from the Tenth Annual Symposium on Arabic Linguistics (pp. 9-45). Amsterdam/Philadelphia: John Benjamins. https://doi.org/10.1075/cilt.153.04ouh

Pesetsky, D., \& Torrego, E. (2001). T to C movement: causes and consequences. In M. Kenstowicz (Ed.), Ken Hale: A Life in Language (pp. 355-426). Cambridge. Mass: The MIT press.

Pesetsky, D., \& Torrego, E. (2006). Probes, Goals, and Syntactic Categories. In Y. Otsu (Ed.), Proceedings of the Seventh Tokio Conference on Psycholinguistics (pp. 25-61). Tokyo: Hituzi Syobo Publishing Company.

Pitsch, H. (2010). Complex verbs between syntax and morphology in Bulgarian. Russian Linguistics, 34, 307329. https://doi.org/10.1007/s11185-010-9059-2

Radford, A. (2009). Analysing English Sentences. Cambridge University Press. https://doi.org/10.1017/CBO9780511801617

Schutze, C. (1997). Infl in Child and adult language: Agreement, Case, and Licensing. Ph. D. Dissertation, MIT, Cambridge, Mass.

Soltan, U. (2007). On Formal Feature Licensing in Minimalism: Aspects of Standard Arabic Morphosyntax. PhD Dissertation, University of Maryland.

Shlonsky, U. (1992). Resumptive Pronouns as a Last Resort. Linguistic Inquiry, 23(3), 443-468.

Wurmbrand, S. (2001). Infinitives: Restructuring and Clause Structure. Berlin: Mouton de Gruyter.

Wurmbrand, S. (2006). Licensing Case. Journal of Germanic Linguistics, 18, 175-234. https://doi.org/10.1017/S1470542706000079

\section{Notes}

Note 1. I write 'Case' with a capital C for the abstract theoretical entity in GB/Minimalism in order to distinguish it from other ordinary element. 
Note 2. Pinna is one of seven members called Pinna and its "sisters"; they almost have the same function, but differ in meaning. Some of them including Pinna can introduce both independent and subordinate clauses. However, this paper limits its discussion to Pinna.

Note 3. The PF component maps the syntactic structure into a PF representation of its phonetic from, resulting in a phonetic spell-out for every word. The LF component, on the other hand, maps the syntactic structure into its counterpart semantic representation.

Note 4. However, Pesetsky and Torrego $(2006,1)$ propose that the relation between Probe and Goal must be established by the operation Merge. This is to say that when Merge combines two elements, a Probe-Goal relation 'must be established between these elements'. They name this the Vehicle requirement on Merge and is formulated as:

Vehicle Requirement on Merge (VRM)

If $\alpha$ and $\beta$ merge, some feature $F$ of $\alpha$ must probe $F$ on $\beta$.

Note 5. See Wurmbrand (2006) for empirical problems in adopting Spec-head relation in Germanic.

Note 6. A transitive head assigns the accusative Case to a NP which it c-commands.

Note 7. Note that the Agree perspective changes the burden of the motivation for movement from Case theory to the Extended Projection Principle (EPP).

Note 8. In the literature (Koopman \& Sporticle, 1991; McCloskey, 1996, 1997), there are at least two positions for the genuine subjects: one is for the thematic subjects that can get a thematic role from the predicate. They occupy a position that is within the thematic shell which can be realized with the VP. The other position is Spec-TP, the functional head c-commands the VP.

\section{Copyrights}

Copyright for this article is retained by the author, with first publication rights granted to the journal.

This is an open-access article distributed under the terms and conditions of the Creative Commons Attribution license (http://creativecommons.org/licenses/by/4.0/). 